\title{
Challenges of cuttings transport in micro-borehole coiled tubing drilling for mineral exploration
}

\author{
M. Kamyab ${ }^{1}$, V. Rasouli ${ }^{1}$, G. Cavanough ${ }^{2}$ \& S. Mandal ${ }^{3}$ \\ ${ }^{I}$ Deep Exploration Technologies Cooperative Research Centre \\ (DET CRC), Department of Petroleum Engineering, \\ Curtin University, Australia \\ ${ }^{2}$ Deep Exploration Technologies Cooperative Research Centre \\ (DET CRC), CSIRO Earth Science and Resource Engineering, \\ Queensland Centre for Advanced Technologies (QCAT), Australia \\ ${ }^{3} A M C$ Research and Development Laboratory, \\ AMC Drilling Fluids and Products, Imdex Limited, Australia
}

\begin{abstract}
Coil tubing (CT) technology has been in use in the oil and gas industry since the 1990s. Since then, the applications of CT have expanded rapidly. Coiled tube drilling can offer more efficient and faster drilling operations resulting in lower operational costs.

Micro-borehole CT drilling (CTD) has been used in oil and gas applications and is very attractive as a method for minerals exploration drilling due to the faster drilling i.e. high rate of penetration (ROP) that can be achieved resulting in reduced drilling costs. Due to the narrow annulus space there is a certain degree of uncertainty with regards to cuttings transport.

In this paper we review the fluid flow and cutting transport models available for conventional drilling. Different aspects of fluid flow in micro-borehole CT will be addressed and discussed. The discussion illustrates the important parameters, including fluid properties, cuttings properties, fluid hydraulics and annular geometry affecting cutting transports in micro-borehole CT drilling in oil and gas as well as mineral exploration.

Keywords: fluid flow, cutting transport, annulus, coiled tubing drilling, microborehole, mineral exploration drilling, slurry loop.
\end{abstract}




\section{Introduction}

In conventional petroleum drilling, drill pipe joints are connected together to form the drill string. Drilling fluid is pumped through the stand pipe, swivel, Kelly and goes through the drill string. Then it passes through the bit nozzles and carries the cuttings up in the annulus to the surface. As drilling progresses, another pipe joint will be added to the existing drill string. However, CT is a continuous steel tube coiled over a drum which is straightened by an injector before it is inserted into the wellbore and when recoiled is placed back onto the reel. So, the drilling fluid has to pass through the entire coiled pipe on the reel and also the straightened section in the well before going to the annulus section. CT unit (CTU) consists of four major sections: 1. Reel: for storage of CT string; 2. Injector head: to straighten and retrieve the CT string; 3. Control cabin: to monitor and control different sections; 4. Power pack: to provide hydraulic and pneumatic power ICoTA [1]. Figure 1 displays the major constituents of the CTU.

Advantages of CT technology over conventional drilling include rapid mobilization and rig-up, eliminating connections and the ability to circulate during tripping. These result in reduced trip and non-productive rig time. Consequently less personnel and crew are required for drilling operation which results in reduced drilling costs. Limitations of CT drilling include limited CT life (due to fatigue), elimination of pipe rotation thus reducing carrying capacity and greater fluid pressure due to high system pressure loss compared to conventional drilling, especially at the top hole [2-4].

In an attempt, the US Department of Energy (US DOE) developed a CT drilling technology for drilling in shallow oil and gas resources $(<5000 \mathrm{ft})$, with a better reservoir imaging ability and reduced environmental footprint Lang [5]. The commonly used deep exploration technique for mineral exploration is diamond coring which is a time consuming process. Replacing this method with CTD of holes with sizes less than 3 inches, i.e. micro-boreholes (MBHs), will save a significant amount of time and money. To bring and reconcile the CT from oil industry into mineral exploration, the differences between the two applications should be conceived.

Table 1 compares the differences between drilling oil and gas wells and mineral explorations. It is important to note that in drilling oil wells the main objective is to reach the target, whereas in mineral exploration drilling collecting samples of ore body and identifying its exact depth is important. Therefore, the drilling fluid has to effectively carry the cuttings to the surface. The cutting size in mineral exploration drilling can be as fine as powder as only fine particles are required for mineral analysis. For example, using an impregnated diamond bits in an experiment $\% 70$ of the cuttings sizes were reported to be less than $63 \mu \mathrm{m}$ (Miller and Ball [6]). So the effect of these smaller size cuttings on the rheology and pressure loss has to be taken into the consideration. 


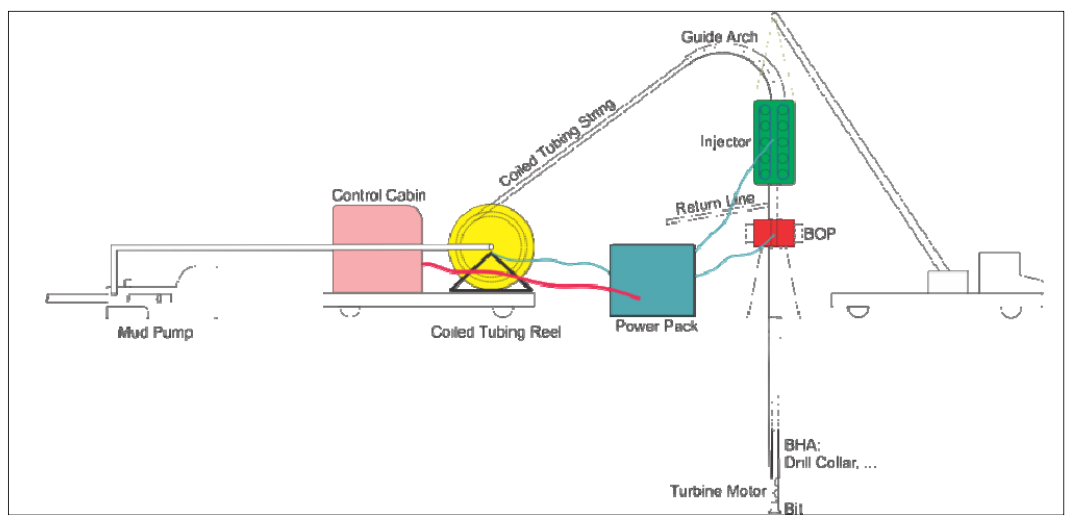

Figure 1: The main components of a CTU.

Table 1: Major difference between drilling in oil and gas and mining industries Exploration drilling [7].

\begin{tabular}{|l||l|l|}
\hline \multicolumn{2}{|l||}{ Oil and gas drilling } & mineral exploration \\
\hline \hline purpose of drilling & producing from the reservoir & sampling \\
\hline final goal & oil or gas production & ore bodies extraction \\
\hline rock types to be drilled & soft to medium sedimentary & hard igneous, metamorphic and sedimentary \\
\hline $\begin{array}{l}\text { exploration techniques } \\
\text { before drilling }\end{array}$ & seismic surveys & $\begin{array}{l}\text { magnetic*, electric, electro-magnetic, induced } \\
\text { polarization, gravimetric, seismic surveys }\end{array}$ \\
\hline drilling type & rotary drilling & diamond coring, RC \\
\hline samples type and size & cuttings & core, cuttings \\
\hline target depth & underground reservoir & surface pit and underground mines \\
\hline drilling bits & tri-cone, PDC & $\begin{array}{l}\text { impregnated diamond core bit, tri-cone } \\
\text { hammer bits }\end{array}$ \\
\hline drilling problems & $\begin{array}{l}\text { kick, fluid loss, wellbore instability, } \\
\text { pipe sticking, hole cleaning, } \\
\text { formation damage }\end{array}$ & these problems don't happen \\
\hline in oil industry it is more complex than in mining \\
\hline drilling fluid & \multicolumn{2}{|l}{} \\
\hline *: Items shown in bold are the main used methods in the industry.
\end{tabular}

The motivation of using micro-borehole Coiled tube drilling (MBHCTD) is to replace current diamond coring technology to make drilling operation faster, cheaper and deeper. Because the drilling process is always faster than coring and there is no need for pipe connection using CT therefore the CTD progresses faster. Smaller hole sizes pose less logistical issues such as site location, environmental footprint, crew and personnel and equipment, drilling fluid, waste materials, rig size. In addition, some drilling problems, such as stuck pipe, which occur during connection, would be avoided [5, 8]. Therefore, MBHCTD seems economically viable for mineral exploration drilling. However, the cuttings generated from drilling have to be representative of the formation being drilled and in this case diamond coring is superior. In diamond coring a core shows the exact depth of the formation. However, in drilling operation because the cuttings 
move along the annulus, there is a lag for the cuttings to reach to the surface. This problem aggravates if the hole angle deviates from vertical. Therefore, understanding the challenges of cuttings transport for mineral exploration drilling is an important aspect to be studied. We use the existing models of cuttings transport in petroleum industry to propose appropriate solutions for specific applications in mineral explorations.

This MBHCTD technique is going to be used as an initial ore bodies evaluation, so when precious minerals have been found among the cuttings using MBHCTD, diamond coring will be used to evaluate the mines with better sampling technique.

In drilling operation, the drilling fluid carries the cuttings to the surface through the annulus space. Then, the drilling fluid mixed with the cuttings goes through the solid removal equipment. These facilities are shale shaker, hydrocyclones, and centrifuge. Because in oil drilling operations the cuttings are large (e.g. $2 \mathrm{~mm}$ or larger), most of the cuttings will be removed with the shale shaker and hydro-cyclones. However, when the cuttings are powder size, centrifuges play an important role in cleaning. The mud cleaning facilities have to separates the cuttings effectively (more than $99 \%$ ) from the drilling mud so the cuttings do not return back to the wellbore. Otherwise, the cuttings will mix with new cuttings and it misleads the analysis of the cuttings. If this happens to precious mineral with less concentration, their exact depth would be questionable.

Cuttings have higher weights than the drilling fluid so they have a tendency to settle down. So, when the drilling fluid carries the cuttings, the cuttings do not have the same velocity as drilling fluid. So, when a drilling fluid particle and cutting particle start moving from the bit to the surface, the drilling fluid components reaches to the surface faster. The difference in time of arrival of cuttings and fluid components, i.e. lag time, is indicated with slip velocity. This is the difference between the fluid velocity and cutting velocity. The parameters which affect slip velocity in the vertical flow are: gravity, buoyancy force, shape of the cuttings and rheology of the drilling fluid. The following equation which is called Stokes' law (ref.) is used to determine the slip velocity: $d_{s}$, cuttings diameter; $\mu$, viscosity of the drilling fluid; $\rho_{s}$, cuttings density; $\rho_{f}$, drilling mud density Stokes [9].

$$
v_{s}=\frac{1}{18} \frac{d_{s}^{2}}{\mu}\left(\rho_{s}-\rho_{f}\right) g
$$

From the equation, one can understand that the important parameter is the cuttings size. Bigger cuttings have higher slip velocity, i.e. settle faster. In our case, the cuttings are powder size, so the slip velocity is much smaller and therefore the slip velocity is low and negligible. So the drilling fluid gelation network could hold the cuttings and carry them with approximately the same velocity they have. The rheological parameters (viscosity) can be adjusted to achieve near zero slip velocity ensuring that no intermixing of the cuttings from different depths while flowing up in the annulus. 


\section{Fluid flow models in annulus}

Before discussing the cuttings transport in the annulus section, it is required to review the models for fluid flow (i.e. no particles). The key parameters which affect fluid flow in the annulus section are fluid properties, flow regime, rheology model, pipe position in the annulus (eccentricity), and inner pipe rotation. Each of these parameters affects the solution of the governing fluid flow equations. Due to the complexity associated with solving rheological and equilibrium equations simultaneously for annulus geometry to develop pressure drop formulae, it is a common approach to simulate annulus geometry with a slot, i.e. two parallel planes. This generates a simpler model that offers reasonably accurate results especially when the annulus diameter ratio, or aspect ratio is greater than $0.3[10,11]$.

A vast amount of research has been performed to study fluid flow in the annulus sections in the past decades, which propose analytical solutions, numerical simulations and experimental studies. Performing experimental simulations in the lab is essential to validate the results of analytical and numerical simulations. For example, Zamora et al. [12] performed a comparison of annulus pressure loss between API standard model and field data. Laird [13] proposed one of the initial fluid flow models that considered laminar flow of Bingham Plastic fluids in concentric annulus geometry. He solved semianalytically the governing fluid flow differential equations. Later on, other investigators [11, 14, 15] improved the laminar fluid flow with the help of analytical, semi-analytical and numerical methods in addition to the laboratory experiments. No analytical solution for turbulent flow exist as unlike laminar flow it does not follow any specific streamlines and therefore analytical solutions cannot be developed for a turbulent flow. Instead, correlations developed based on experimental tests have been presented for modelling turbulent flows [10, 16, 17].

\section{Cuttings transport in the annulus space}

In slurry transport, the liquid phase carries the solid particles. An example of this is the cutting transport in the annulus space in oil and gas or mineral exploration drilled wells. However, slurry transport has application in many other fields including foods, pharmaceuticals, chemicals, construction, and power generation industries $[18,19]$.

In oil and gas applications, research in studying cuttings transport in vertical wells, which is easier to model as the fluid velocity and the gravity force are collinear vectors but acting in opposite directions has been conducted. However, in deviated wells the gravity force is acting downward whereas the fluid velocity vector is aligned with the borehole wall. If the vertical component of the fluid flow cannot hold the cuttings in the flow stream, the cuttings will deposit at the low side of the borehole which may cause some hole cleaning problems. When the cuttings deposit, it is hard to bring them to the main stream because the local velocity near the wall is very low (Ramadan et al. [20]). 

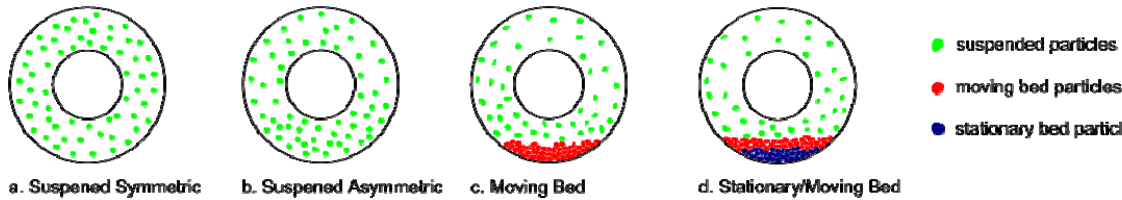

- moving bed particles

- stationary bed particles

Figure 2: $\quad$ Flow patterns of slurry flow in horizontal concentric annulus (after Kelessidis and Bandelis [4]).

Improper hole cleaning causes many problems such as extreme overpull on trips, hole pack-off, stuck pipe, higher drag and torque, slower ROP, excessive ECD (equivalent circulating density), increased fluid loss and formation fracture. These problems are aggravated in deviated and horizontal wells [21, 22].

Doron et al. [19] introduced two-layer modelling of slurry flow in a pipe. In this model if a solid bed formed then it is either a stationary or a moving bed. This model was later extended to three-layer model: stationary bed at the bottom, suspended layer at the top, and moving bed in between, Doron and Barnea [23]. It is to be noted that not all the layers always exist but depends on the flow rate, for example, if the flow rate is high enough only suspended layer occurs. Figure 2 shows different flow patterns in a horizontal annulus having different slurry velocities. When the velocity is very high the solid particles distribute homogenously over the annulus. Reduction of the velocity diminishes the homogeneity and cuttings starts to aggregate at the bottom due to gravity and if the velocity decreases more, a moving solid bed produces. Further drop in velocity causes formation of a stationary bed overlayed by a moving bed. The main parameters that affect the flow profiles are: liquid velocity; solid loading (ROP), solid properties (density, size and dimensional shape) and liquid properties (density and rheology) [2, 4].

In addition to the aforementioned models many models have been developed for layer modelling of cuttings transport in the annulus space [2, 20, 21, 24]. Investigators utilized different mass and momentum balance equations to understand the characteristics of cuttings transport. Then they present different parameters that controls the cuttings transport phenomena.

Doron et al. [19] and Doron and Barnea [25] mentioned that the mixture viscosity can be assumed as liquid viscosity because the coarse particles do not affect the viscosity of the whole mixture. However, in the applications discussed here the cuttings sizes are very small with larger surface area which makes them much more surface interactive with the mud and cosiness between the particles through large physico-chemical interaction and therefore they will alter the viscosity of the mixture compared to coarser particles. Fangary et al. [26] stated that the pressure loss for small particles in turbulent flow will be higher because they will mix with the liquid and they do not dampen the flow compared to coarser particles which dampen the turbulence effect.

The main application of slurry transport in mining industry is for mineral transportation using pipelines. A famous project of this kind was carried out by Black Mesa in the US in 1970 where 4.8 million tons of coal was transported over a distance of 273 miles in a year [27]. 


\section{Cuttings transport efficiency}

Cuttings transport efficiency is controlled by various parameters including the following:

- Velocity or flow rate: this is inevitably the most important parameter among others, because increasing the fluid flow velocity produces more energy to carry the cuttings $[2,4,19,21,23,24]$.

- Drilling fluid rheology: Nguyen and Rahman [24] reported that higher viscosity muds result in a better cuttings transport performance in horizontal wells. This is in agreement with experimental work of Peden et al. [28] but contradicts the idea presented by Hyun et al. [29] that less viscous fluid with high velocity under turbulent flow regime result in better cuttings transport performances. Pilehvari et al. [30] recommended that turbulent flow regime in horizontal and highly deviated wells, regardless of the viscosity of the fluid, will lead to good cuttings transport. This shows that a decisive rheological property of the drilling fluid for the purpose of cuttings transport is not available. Therefore this has to be tested for MBHCTD in mineral exploration as well.

- Mud weight: Nguyen and Rahman [24] stated that this parameter has a considerable effect on cuttings transport in horizontal wells which can result in reduction of the bed thickness when it increases. However, Li et al. [21] showed that increasing the mud weight has a small to moderate decrease on cutting beds thickness.

- Particle density: a reduction in particle density can significantly reduce the cuttings concentration in the annulus section Nguyen and Rahman [24]. However, this parameter cannot be controlled as depends on formation density.

- Particle diameter: this parameter has a very small effect on bed thickness Li et al. [21].

- Eccentricity: it disadvantageously alters the cutting transport efficiency significantly. So, higher pump rate are required to compensate this problem. In an experiment performed by Kelessidis et al. [18] fully suspended layer occurred at $0.77 \mathrm{~m} / \mathrm{s}$ and $1.61 \mathrm{~m} / \mathrm{s}$ for concentric and fully eccentric annulus geometry, respectively.

Nguyen and Rahman [24] and Hyun et al. [29] mentioned that the fully suspended flow occur at annular velocity of 4 to $5 \mathrm{ft} / \mathrm{s}$ that is upper limit of the flow that can be achieved in CTD. However, the cutting transportation value for vertical conventional drilling is between 2 to $3 \mathrm{ft} / \mathrm{s}$ Hyun et al. [2].

Drill pipe rotation mechanically agitates the cuttings and it helps cutting carrying capacity. Reciprocating motion of pipes is another option but it is not as effective as pip rotation. Therefore, in CTD where the pipe rotation is not available, reciprocating motion and increasing flow rate would help API RP D13 [22]. 


\subsection{Cuttings transport in MBHs}

A part of the problems associated with cuttings transport in MBHs in petroleum industry applications such as hydraulic problems still persist [3, 8, 18, 31]. Albright et al. [31] reported that in very narrow annulus space, cuttings transport is an important aspect to study in particular in highly deviated and horizontal boreholes.

Albright et al. [31] proposed the use of a high pressure-low flowrate design to optimize the hydraulic power for higher rate of penetration (ROP). However, when low flowrate criteria is chosen then higher viscosity fluids have to be used to hold and carry the cuttings. Two factors that constrain the flow rates are pump pressure and downhole motor/turbine/BHA (Leising and Walton [3]). So, the flow rate has to be specified in a limited boundary. For the design of downhole motor, Los Alamos National Lab (LANL) stated that high pressure-low flowrate design is the best choice but further studies are needed to investigate the best option for micro size boreholes drilled in hard rocks [32].

The flowrate has to be optimally determined in a way so the concentration of the cuttings in any point in the annulus is lesser than $5 \%$ by volume $[4,31]$. Low flowrate increases the cutting concentration and therefore the pressure loss will increase due to solid interactions. On the other hand, if the flowrate is much higher than the optimum value, the ROP will not be at its optimum value because of the hydraulic power provided will not be optimum. Therefore, the optimum values for these three parameters (i.e. low flow rate, high rate of penetration, and low solid concentration) should be determined (Albright et al. [31]).

Albright et al. [31] performed some hydraulic power transport models assuming a Power-Law fluid but ignored the cuttings transport effect. They concluded that the current simulators underestimate the pressure loss in the annulus section. This indicates the need for better fluid models and also to include the cuttings transport effect into the model for more realistic simulations.

Among the numerical simulaiton and experimental studies in cuttings transport modelling in the annulus space, few cases reported on MBHs. One of the experiments was done by Kelessidis et al. [18] in a borehole with a diameter of $7 \mathrm{~cm}$ and pipe outside diameter of $5 \mathrm{~cm}$. In their study they used a horizonal hole configuration, glass beads as particles, paricle diameter of $2 \mathrm{~mm}$ and solid concentration of $2-4 \%$. The hole configuration is only horizontal and they did not consider deviated and vertical holes. Also, they used glass beads with sizes of $2 \mathrm{~mm}$ which are very big compared to particle sizes we experience in the applications for hard rock drilling.

\section{Hard rock cuttings transport models}

There is no study reported on cuttings transport in hard rock applications. The need for in-depth investigation in this area is important for the applications mentioned in this study.

The drilling fluid that is currently used for diamond coring is mainly water. This is used for coring purpose; however investigations are needed to determine 
the suitable mud for cuttings transport purpose. There are a lot of discrepancies between what rheological properties are more appropriate in other sciences and especially in petroleum industry, this is more challenging for intact area of cuttings transport for mineral exploration CTD. In addition, the effect of small particle sizes on rheology has to be taken into consideration which was ignored by other researchers.

If MBHCTD is used to be a substitute for diamond coring it should have the ability to show the exact depth of the cuttings when they arrive at the surface. Cutting transport for this purpose is not only referring to carry the cutting out of the wellbore but also to determine the exact depth of the cuttings. This means that cutting deposition, especially in horizontal and deviated wells, should be avoided. If deposition occurs, the new cuttings will mix with previously deposited cuttings and therefore the exact depth is questionable.

In addition, particle density of the cuttings in mineral exploration drilling is higher than that of oil and gas industry, so the gravity causes them to settle faster. Particle density has to be taken into consideration particularly for precious minerals such as iron ore, zinc and gold which have higher densities compared to normal cuttings and can deposit more easily. Due to the lack of adequate knowledge in the area of cuttings transport in hard rock drilling, particularly with reference to the applications stated above we propose both numerical simulations and lab experimental work for this purpose. Figure 3 shows schematic of a slurry loop that we are proposing to study cuttings transport in annular space. The controlling variables in this design include fluid properties (mud type, density and rheology), cutting concentration (ROP), cutting size, hole angle (horizontal, deviated and vertical), flow rate and annulus space size (hole and inner pipe sizes).

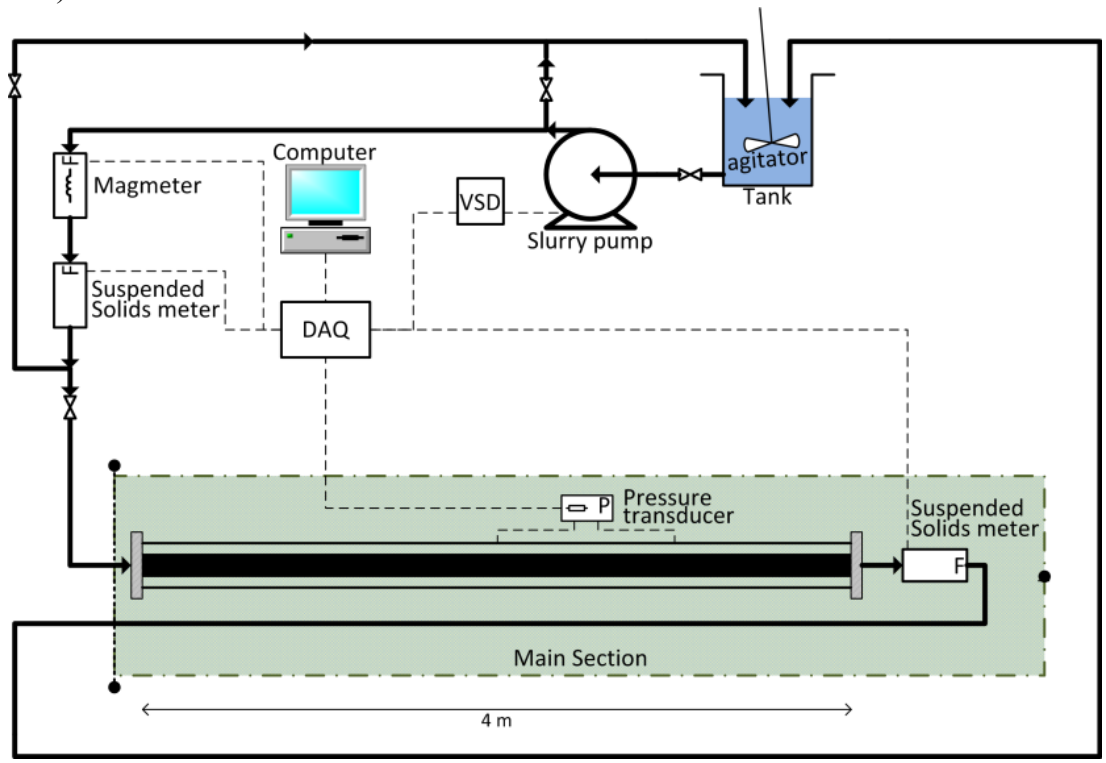

Figure 3: Schematic of a proposed slurry loop for cuttings transport studies. 
The plan is to model cuttings transport similar to the field conditions for hard rock micro-borehole CT drilling. For example, the experiments reported in the previous sections by other investigators performed using synthetic solid particles such as glass beads with sizes larger than $2 \mathrm{~mm}$. However, the experiments in this study will be on very small size and dense particles. The results of lab tests would expect to provide information about cuttings transport characteristics in hard rock drilling.

\section{Conclusions}

In this paper a review of current fluid flow and cutting transport models for petroleum applications were presented. Then, the challenges associated with cuttings transport in micro-boreholes were discussed. After that, the differences between oil and gas and mineral exploration drilling enumerated to find the differences in cuttings transport criteria as well. Still, there are a lot of discrepancies in some aspects such as drilling fluid type, rheological properties and finding the optimum flow rate in the petroleum industry. In addition to these problems, cuttings transport issues related to micro-borehole coiled tube drilling in hard rocks should be stressed.

The presented discussion demonstrates the need for further investigations of cuttings transport in micro-borehole coiled tube drilling in hard rocks.

\section{Acknowledgement}

The authors would like to express their sincere appreciation to the Deep Exploration Technologies Cooperative Research Centre (DET-CRC) for their financial supports towards this project (DET CRC Document 2012/037).

\section{References}

[1] An introduction to coiled tubing, ICoTA, 2005, http://www.icota.com /publications/ICoTA\%20Publication\%20Intro\%20to\%20CT.pdf

[2] Hyun, C., S.N. Shah and S.O. Osisanya. A three-layer modeling for cuttings transport with coiled tubing horizontal drilling. SPE Annual Technical Conference and Exhibition, SPE: Dallas, Texas, 2000.

[3] Leising, L.J. and I.C. Walton, Cuttings-Transport Problems and Solutions in Coiled-Tubing Drilling. SPE Drilling \& Completion, 17(1), pp. 54-66, 2002.

[4] Kelessidis, V.C. and G.E. Bandelis, Flow patterns and minimum suspension velocity for efficient cuttings transport in horizontal and deviated wells in coiled-tubing drilling. SPE Drilling \& Completion, 19(4), pp. 213-227, 2004.

[5] Lang, R., Microhole Technology, U.S. Department of Energy, 2006, microtech.thepttc.org/program_brochure_short.pdf 
[6] Miller, A. and A. Ball, Rock drilling with impregnated diamond microbits An experimental study. International Journal of Rock Mechanics and Mining Sciences \& Geomechanics Abstracts, 27(5), pp. 363-371, 1990.

[7] Exploration drilling, Atlas Copco, 2010, www.atlascopco.com

[8] Microhole initiative - workshop summary, Spears \& Associates, Inc, 2003, www.spearsresearch.com

[9] Stokes, G.G., Transactions of the Cambridge Philosophical Society, 9, pp. 8, 1851.

[10] Founargiotakis, K., V.C. Kelessidis and R. Maglione, Laminar, transitional and turbulent flow of Herschel-Bulkley fluids in concentric annulus. The Canadian Journal of Chemical Engineering, 86(4), pp. 676-683, 2008.

[11] Hanks, R.W., The axial laminar flow of yield-pseudoplastic fluids in a concentric annulus. Industrial \& Engineering Chemistry Process Design and Development, 18(3), pp. 488-493, 1979.

[12] Zamora, M., S. Roy and K. Slater. Comparing a basic set of drilling fluid pressure-loss relationships to flow-loop and field data. AADE 2005 National Technical Conference and Exhibition, American Association of Drilling Engineers: Houston, Texas, 2005.

[13] Laird, W., Slurry and Suspension Transport - Basic Flow Studies on Bingham Plastic Fluids. Industrial \& Engineering Chemistry, 49(1), pp. 138-141, 1957.

[14] Iyoho, A. and J. Azar, An accurate slot-flow model for non-Newtonian fluid flow through eccentric annuli. SPE Journal, 21(5), pp. 565-572, 1981.

[15] Hussain, Q.E. and M.A.R. Sharif, Numerical modeling of helical flow of viscoplastic fluids in eccentric annuli. AIChE journal, 46(10), pp. 19371946, 2000.

[16] Hartnett, J.P. and M. Kostic, Turbulent friction factor correlations for power law fluids in circular and non-circular channels. International communications in heat and mass transfer, 17(1), pp. 59-65, 1990.

[17] Sorgun, M., I. Aydin, E. Ozbayoglu and J.J. Schubert, Mathematical Modeling of Turbulent Flows of Newtonian Fluids in a Concentric Annulus with Pipe Rotation. Energy Sources, Part A: Recovery, Utilization, and Environmental Effects, 34(6), pp. 540-548, 2012.

[18] Kelessidis, V.C., G.E. Bandelis and J. Li, Flow of dilute solid-liquid mixtures in horizontal concentric and eccentric annuli. Journal of Canadian Petroleum Technology, 46(5), pp. 56-61, 2007.

[19] Doron, P., D. Granica and D. Barnea, Slurry flow in horizontal pipesexperimental and modeling. International Journal of Multiphase Flow, 13(4), pp. 535-547, 1987.

[20] Ramadan, A., P. Skalle and A. Saasen, Application of a three-layer modeling approach for solids transport in horizontal and inclined channels. Chemical Engineering Science, 60(10), pp. 2557-2570, 2005.

[21] Li, Y., N. Bjorndalen and E. Kuru, Numerical modelling of cuttings transport in horizontal wells using conventional drilling fluids. Journal of Canadian Petroleum Technology, 46(7), pp. 9-15, 2007. 
[22] Rheology and hydraulics of oil-well fluids, American Petroleum Institute, 2010

[23] Doron, P. and D. Barnea, A three-layer model for solid-liquid flow in horizontal pipes. International Journal of Multiphase Flow, 19(6), pp. 1029-1043, 1993.

[24] Nguyen, D. and S.S. Rahman, A three-layer hydraulic program for effective cuttings transport and hole cleaning in highly deviated and horizontal wells. SPE Drilling \& Completion, 13(3), pp. 182-189, 1998.

[25] Doron, P. and D. Barnea, Flow pattern maps for solid-liquid flow in pipes. International Journal of Multiphase Flow, 22(2), pp. 273-283, 1996.

[26] Fangary, Y., A. Ghani, S. El Haggar and R. Williams, The effect of fine particles on slurry transport processes. Minerals engineering, 10(4), pp. 427-439, 1997.

[27] Black Mesa pipeline. 2012; Available from: http://goo.gl/B3DAS

[28] Peden, J.M., J.T. Ford and M.B. Oyeneyin. Comprehensive experimental investigation of drilled cuttings transport in inclined wells including the effects of rotation and eccentricity. European Petroleum Conference, SPE: The Hague, Netherlands, 1990.

[29] Hyun, C., S.N. Shah and S.O. Osisanya, A three-segment hydraulic model for cuttings transport in coiled tubing horizontal and deviated drilling. Journal of Canadian Petroleum Technology, 41(6), pp. 32-39, 2002.

[30] Pilehvari, A., J.J. Azar and S.A. Shirazi, State-of-the-art cuttings transport in horizontal wellbores. SPE Drilling \& Completion, 14(3), pp. 196-200, 1999.

[31] Albright, J., D. Dreesen, D. Anderson, J. Blacic, J. Thomson and T. Fairbanks, Road map for a 5000-ft microborehole, Los Alamos National Laboratory, http://goo.gl/yJzdR

[32] Current capabilities of hydraulic motors, air/nitrogen motors, and electric downhole motors, RIO Technical Services: 4200 South Hulen, Suite 630, Fort Worth, Texas 76109, 2004, http:/www.netl.doe.gov/technologies/oilgas/publications/EP/30429Tsk1FinalRpt.pdf 